\title{
Vasculitis, Atherosclerosis, and Altered HDL Composition in Heme-Oxygenase-1-Knockout Mice
}

\author{
Kazunobu Ishikawa, ${ }^{1}$ Mohamad Navab, ${ }^{2}$ and Aldons J. Lusis ${ }^{2}$ \\ ${ }^{1}$ The First Department of Internal Medicine and Center for Medical Education and Career Development, \\ Fukushima Medical University, 1 Hikarigaoka, Fukushima 960-1625, Japan \\ ${ }^{2}$ Division of Cardiology, Department of Medicine, David Geffen School of Medicine at UCLA, Los Angeles, CA 90095-1679, USA
}

Correspondence should be addressed to Kazunobu Ishikawa, kishikaw@fmu.ac.jp

Received 12 October 2011; Revised 21 November 2011; Accepted 29 November 2011

Academic Editor: Nader G. Abraham

Copyright ( $) 2012$ Kazunobu Ishikawa et al. This is an open access article distributed under the Creative Commons Attribution License, which permits unrestricted use, distribution, and reproduction in any medium, provided the original work is properly cited.

To elucidate roles of heme oxygenase-1 (HO-1) in cardiovascular system, we have analyzed one-year-old HO-1-knockout mice. Homozygous HO-1-knockout mice had severe aortitis and coronary arteritis with mononuclear cellular infiltration and fatty streak formation even on a standard chow diet. Levels of plasma total cholesterol and HDL were similar among the three genotypes. However, homozygous HO-1-knockout mice had lower body weight and plasma triglyceride. HO-1-deficiency resulted in alteration of the composition of HDL. The ratio of apolipoprotein AI to AII in HO-1-knockout mice was reduced about 10-fold as compared to wild-type mice. In addition, paraoxonase, an enzyme against oxidative stress, was reduced less than 50\% in HO1-knockout mice. The knockout mice also exhibited significant elevation of plasma lipid hydroperoxides. This study using aged $\mathrm{HO}-1$-knockout mice strengthened the idea that HO-1 functions to suppress systemic inflammation in artery wall and prevents plasma lipid peroxidation.

\section{Introduction}

Heme oxygenase (HO) oxidatively catalyzes heme to biliverdin, carbon monoxide, and free iron using NADPHcytochrome P450 reductase as an electron donor [1-3]. A number of studies suggest a potential protective function of this enzyme against oxidative stress under various conditions with transcriptional activation of heme oxygenase-1 (HO-1) $[4,5]$. The antioxidant activity of $\mathrm{HO}$ derives from both the elimination of prooxidant heme and the biological activities of its products. Biliverdin and its metabolite by biliverdin reductase, bilirubin, effectively inhibit LDL oxidation $[6$, 7]. Free iron regulates ferritin synthesis through an ironresponsive element [8]. Ferritin has been shown to have cytoprotective effects against oxidative injuries [9]. Carbon monoxide $(\mathrm{CO})$ modulates the activity of soluble guanylate synthetase like nitric oxide [10] and p38 mitogen-activated kinase activity [11].

Accumulating evidence suggests that oxidized LDL (oxLDL) plays an important role during the early phases of atherogenesis via its proinflammatory properties [5]. We recently reported that HO-1 is remarkably induced by mildly oxLDL in both endothelial cells and smooth muscle cells [12]. HO-1 expression was also highly responsive to oxidized bioactive oxidized phospholipids existing in LDL [12]. In addition, using artery wall cocultures we found that HO-1 inhibits oxLDL-dependent monocyte chemotaxis through its products bilirubin and biliverdin [12]. We then performed in vivo studies to examine the role of $\mathrm{HO}-1$ on the development of atherosclerosis. HO-1 was highly expressed in atherosclerotic lesion in C57BL/6J, apoE-knockout, and LDL-receptor-knockout mice [13]. When we modulate HO expression in high-fat-fed LDL-receptor knockout mice, HO inhibition significantly resulted in the progression of atherosclerotic lesion formation compared to the mice in which HO was induced [13]. These results lead us to hypothesize the protective roles of $\mathrm{HO}-1$ for atherogenesis.

High-density lipoproteins (HDLs) are considered to work for antiatherogenesis. These antiatherogenic properties have been explained by reverse cholesterol transport from 
cells to liver [14]. However, previous studies revealed that HDL itself works as an antioxidant for minimally oxidized low-density lipoproteins [15] and that paraoxonase and apolipoprotein AI in HDL play an important role as antioxidants [16, 17]. However, it is reported that oxidative modification of HDL loses the effect to stimulate efflux of cholesterol from foam cells [18] and that oxidized HDL activates platelets similar to oxidized LDL [19].

To further strengthen the idea that HO-1 functions as an anti-inflammatory enzyme in artery wall and that HO-1 exhibits antioxidative effects on plasma lipoproteins, we analyzed one-year-old HO-1-knockout mice bred on a standard chow diet. Studies using HO-1 knockout mice $[4,20,21]$ revealed that (i) HO-1-homozygous-knockout $\left(\mathrm{HO}-1^{-/-}\right)$mice develop an anemia with accumulation of iron in liver and kidney, (ii) cultured $\mathrm{HO}-1^{-/-}$embryonic fibroblasts produce high free radicals when exposed to hydrogen peroxides, paraquat, or cadmium chloride, (iii) HO- $1^{-/-}$mice are vulnerable to mortality when challenged with endotoxin, and (ix) HO-1 expression ensures to survive cardiac xenograft.

In this study, we examined artery walls and plasma lipoproteins of male HO-1-knockout mice between 1- and 1.5year old which were bred on a standard chow diet. HO-1knockout mice had severe infiltration of mononuclear cells at their ascending aortic wall and coronary arteries and small atherosclerotic lesion in aortic sinus. In HO-1 knockout mice, HDL appears to be oxidized. Furthermore, the composition of apolipoprotein AI and AII in HDL altered. These results show HDL oxidation in HO-1-knockout mice. In addition, HO-1-knockout mice showed lower plasma paraoxonase level and higher lipid peroxide level, suggesting that the absence of HO-1 resulted in the oxidation of plasma lipoproteins and activate inflammatory responses in arterial wall.

\section{Materials and Methods}

2.1. Reagents. Reagents utilized were obtained from Sigma unless otherwise specified.

2.2. Animal Handling and Procedures. All animal experiments were conducted in accordance with the guidelines of the UCLA and Fukushima Medical University Animal Research Committee. The generation of mice containing targeted disruption of the HO- 1 gene was done as previously described [4]. HO-1-deficient mice were generated with C57BL/6J and 129/sv mixed genetic background. C57BL/6J mice for backcross were purchased from the Jackson Laboratory (Bar Harbor, ME). The mice were fed a standard rodent chow diet containing $4 \%$ (wt/wt) fat and $<0.04 \%$ (wt/wt) cholesterol (Oriental Bio, Tsukuba, Japan). Animals were housed four to five per cage and maintained in a temperature-controlled room with a 12-hour light/dark cycle, and animals were strictly monitored for microorganisms.

2.3. Atherosclerotic Lesion Analysis. Following sacrifice, the heart and proximal aorta were excised and washed in phosphate-buffered saline to remove blood. The basal portion of the heart and proximal aorta were embedded in OCT compound (Tissue Tek, Elkhart, IN), frozen on dry ice, and stored at $-70^{\circ} \mathrm{C}$ until they were sectioned. Serial $10-\mu \mathrm{m}$ cryosections were collected on poly-D-lysine-coated slides, stained with oil red $\mathrm{O}$ and hematoxylin, and examined by light microscopy. Atherosclerotic lesion area was calculated using serial sections of the first $400 \mu \mathrm{m}$ of the ascending aorta as previously described [22]. Hematoxylin-eosin and Elastica Van Gieson staining were done with the paraformaldehyde fixed sections.

2.4. Hematocrit, Plasma Lipoprotein Analyses, and Lipid Peroxidation Assay. Blood was collected from the retro-orbital plexus of mice fasted overnight using heparin-coated capillaries (Fisher Scientific) into a heparin-treated Microtainer tube (Becton Dickinson) and centrifuged at $4^{\circ} \mathrm{C}$. The hematocrit was determined by the use of capillary microhematocrit technique in blood obtained. Plasma cholesterol and triglyceride concentrations were determined enzymatically as described previously [23].

2.5. Plasma Lipoproteins and Lipid Analyses. Lipoprotein fractions from pooled mice plasma were isolated by fast performance liquid chromatography [23]. Lipoprotein concentrations are expressed according to their protein content. The characterization of isolated HDL fractions from mouse plasma has previously reported [24]. The protein content of lipoproteins was measured using the method of Lowry et al. [25]. HDL fraction was electrophoresed by $1 \%$ agarose gel and stained with Nile Red. SDS-PAGE with $4-20 \%$ gradient gel was performed according to the procedure of Laemmli [26].

2.6. Paraoxonase Assay. Paraoxonase activities were assayed using paraoxon as substrate [27]. The cuvette contained $1.0 \mathrm{mM}$ paraoxon in $20 \mathrm{mM}$ Tris/ $\mathrm{HCl}(\mathrm{pH} 8.0)$. The reaction was initiated by the addition of the plasma, and the increase in the absorbance at $405 \mathrm{~nm}$ was recorded. Blanks were included to correct for spontaneous hydrolysis of paraoxon. Enzymatic activity was calculated from the molar extinction coefficient $1310 \mathrm{M}^{-1} \mathrm{~cm}^{-1} .1$ unit of paraoxonase activity is defined as $1 \mathrm{nmol}$ of 4-nitrophenol formed per min under the above assay conditions [27]. For purified paraoxonase standard solutions, paraoxonase isoforms were isolated as described previously [27].

2.7. Other Procedures. Plasma lipid peroxidation as a malondialdehyde was measured with a kit from Oxis (Portland, OR). All values are expressed as means \pm SD. Significant difference was determined by one-way ANOVA analysis with Fisher's post hoc test. $P<0.05$ was considered significant.

\section{Results and Discussion}

3.1. Aortitis, Coronary Arteritis, and Atherosclerosis in HO-1Knockout Mice. To elucidate the effect of HO-1 on vascular system, we examined male HO-1-knockout mice aged over 1 year which were bred on a standard rodent chow diet. 

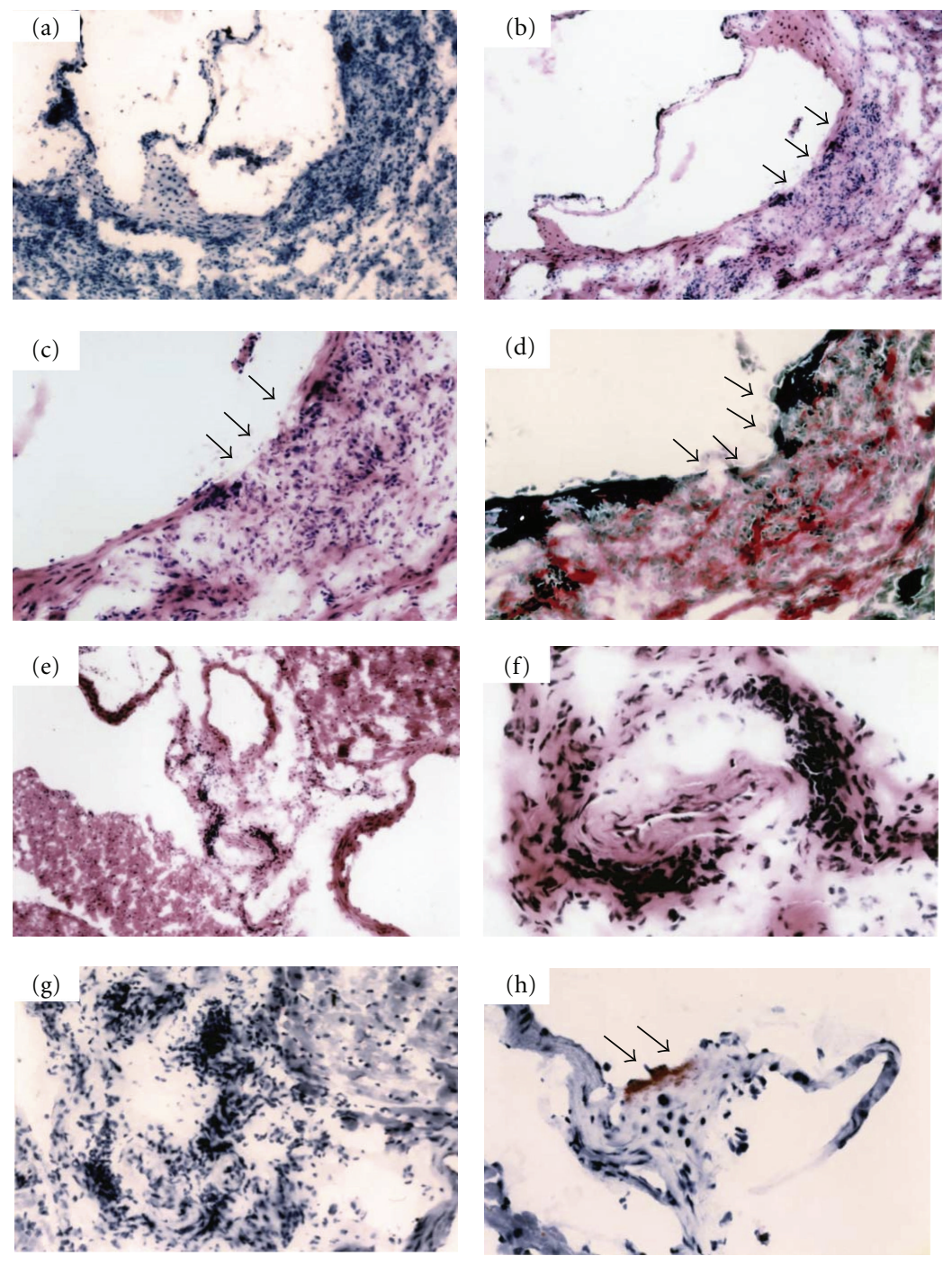

FIGURE 1: Severe aortitis, coronary arteritis and small atherosclerotic lesion on a standard rodent chow diet after 1 year old of HO-1 ${ }^{-/-}$mice. (a, g, h) Oil red O staining. (b, c, e, f) Hematoxylin- eosin staining. (d) Elastica Van Gieson staining. (d) Elastic fibers in the vessel walls are torn at the site of severe mononuclear cell infiltration. Magnifications at (a, e) $\times 40$, (b) $\times 100,(c, d) \times 200$, and (f, g, h) $\times 400$. Predominant sites of aortitis (b, c, d) and initial fatty streak formation (h) are indicated by arrows. These photomicrographs are representative of numerous sections examined.

TABLE 1: Body weight and plasma lipid levels of HO-1-knockout mice.

\begin{tabular}{lccc}
\hline HO-1 genotype & $+/+(n=7)$ & $+/-(n=6)$ & $-/-(n=5)$ \\
\hline Body weight $(\mathrm{g})$ & $45.6 \pm 4.3$ & $43.8 \pm 3.8$ & $30.6 \pm 3.9^{*}$ \\
Hematocrit $(\%)$ & $46 \pm 4$ & $44 \pm 2$ & $41 \pm 2$ \\
Total cholesterol $(\mathrm{mg} / \mathrm{dL})$ & $92 \pm 18$ & $87 \pm 11$ & $86 \pm 15$ \\
Triglyceride $(\mathrm{mg} / \mathrm{dL})$ & $106 \pm 38$ & $26 \pm 4$ & $14 \pm 3^{*}$ \\
HDL-cholesterol $(\mathrm{mg} / \mathrm{dL})$ & $73 \pm 8$ & $72 \pm 11$ & $65 \pm 9$ \\
Free Fatty Acid $(\mathrm{mg} / \mathrm{dL})$ & $43 \pm 7$ & $41 \pm 8$ & $36 \pm 3$ \\
\hline
\end{tabular}

Lipid levels are given in $\mathrm{mg} / \mathrm{dL} \pm$ S.D. Values for lipid levels on a standard chow diet were from mice of 50\% C57BL/6 and 50\% $129 / \mathrm{Sv}$ genetic background. ${ }^{*} P<0.05$.

These mice had a mixed genetic background of $129 \mathrm{~Sv}$ and $\mathrm{C} 57 \mathrm{BL} / 6 \mathrm{~J}$. $\mathrm{HO}-1^{-/-}$mice had severe infiltration of mononuclear cells at their ascending aortic wall (100\%) (Figures 1(a) and 1(b)). This infiltration was transmural, and the intimal elastic laminal structure was severely destroyed (Figures 1(c), and 1(d)). This mononuclear cellular infiltration was not only observed at aorta but also observed at coronary arteries (Figures $1(\mathrm{e}), 1(\mathrm{f})$, and $1(\mathrm{~g})$ ). Oil red $\mathrm{O}$ staining revealed small atherosclerotic lesion in aortic sinus of $\mathrm{HO}^{-1} \mathrm{1}^{-/-}$mice even under a standard chow diet though wild-type mice did not develop such lesions (Figure 1(h)). These inflammatory changes of arteries were also observed in heterozygous mice; however, this was less frequently. It is unclear whether these arterial inflammations in HO-1deficient mice are the response against microorganisms or autoimmune response [28].

3.2. Altered HDL Properties in HO-1-Knockout Mice. Table 1 shows body weights and plasma lipid levels of 


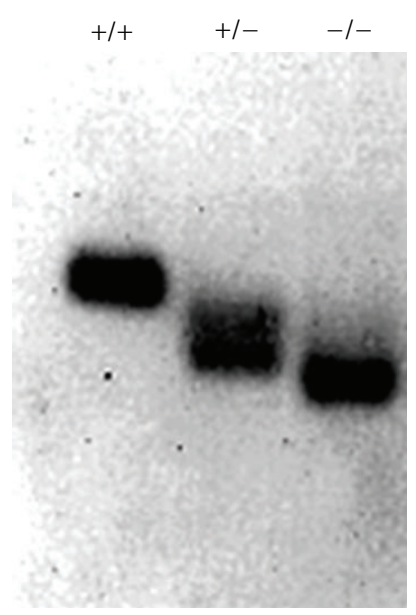

(a)

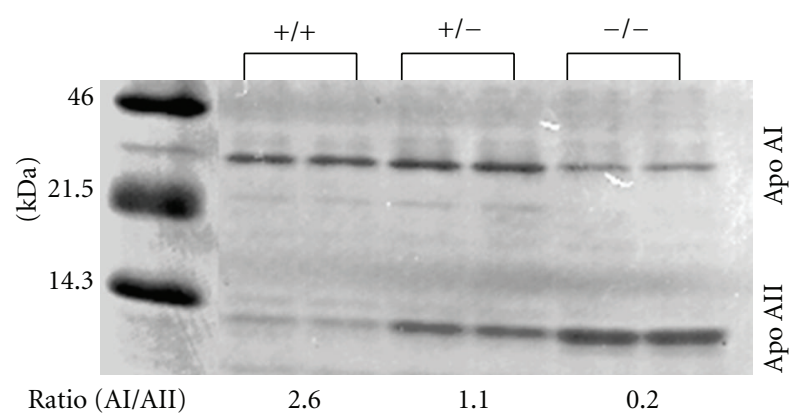

(b)

Figure 2: (a) Agarose electrophoresis of HDL in HO-1-knockout mice. $11 \mu \mathrm{g}$ protein of HDL fraction was electrophoresed in 1\% agarose gel and stained with Nile Red. (b) Change of Apolipoprotein AI/AII ratio in HO-1-knockout mice. $1 \mu \mathrm{g}$ protein HDL was subjected to SDS-PAGE and stained with Nile Red.

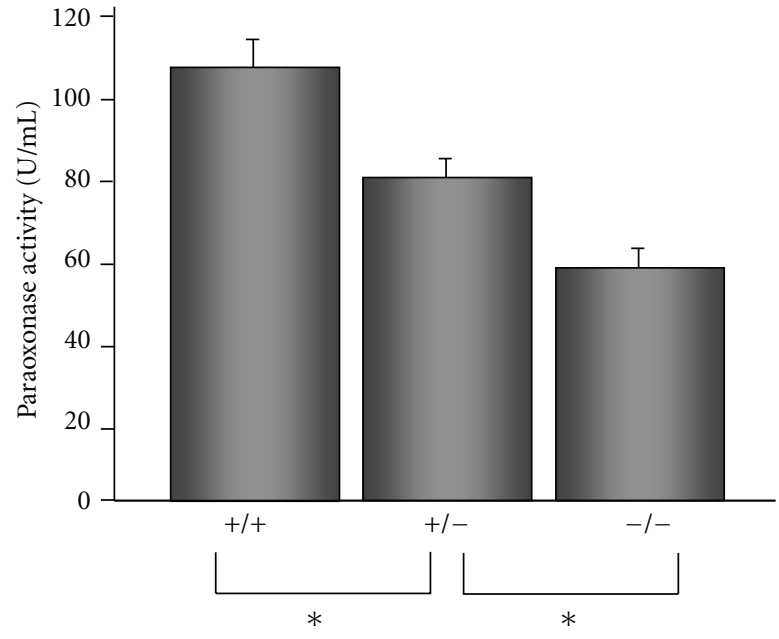

(a)

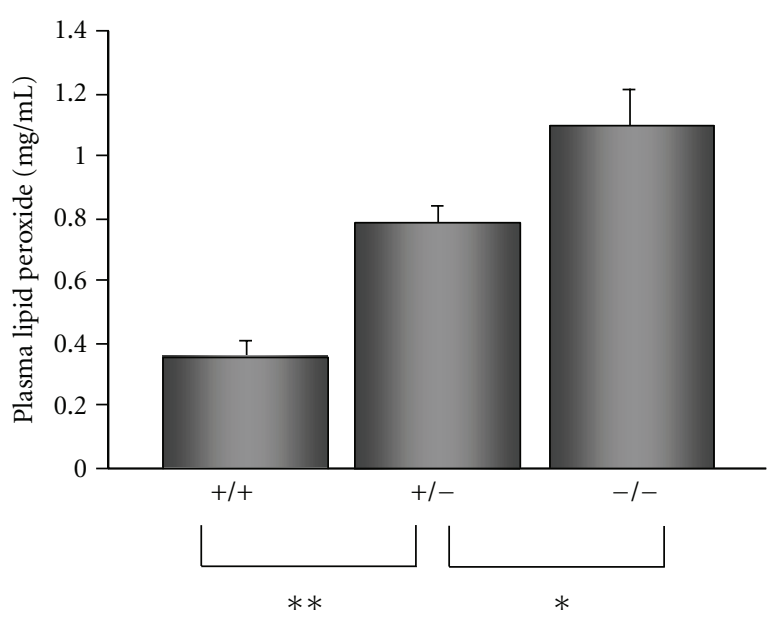

(b)

FIgure 3: (a) Plasma paraoxonase activities in HO-1-knockout mice. PON activities were determined using arylesterase as substrate and are given as a percentage \pm S.D. (b) Plasma lipid hydroperoxide levels in HO-1-knockout mice. Estimates of lipid peroxidation products were obtained by malondialdehyde (MDA) measurements of plasma. Data represents mean \pm S.D. from duplicate. Asterisks represent statistically significant differences $\left({ }^{*} P<0.05, * * P<0.01\right)$.

HO-1-knockout mice analyzed. HO-1 ${ }^{-/-}$mice were significantly lighter than $\mathrm{HO}-1$ wild-type $\left(\mathrm{HO}_{-} 1^{+/+}\right)$and $\mathrm{HO}-$ 1-heterozygous-knockout $\left(\mathrm{HO}-1^{+-}\right)$mice. There were no differences in total cholesterol, HDL, and free fatty acid levels among three genotypes; however, triglyceride levels of $\mathrm{HO}$ $1^{-/-}$and $\mathrm{HO}^{-1^{+/-}}$were much lower than those of $\mathrm{HO}-$ $1^{+/+}$mice. HDLs were prepared by discontinuous density gradient ultracentrifugation from pooled fresh plasma of each genotype, electrophoresed on $1 \%$ agarose gel and stained with Nile Red. $11 \mu \mathrm{g}$ HDL of $\mathrm{HO}-1^{-1-}$ and ${ }^{+/-}$mice runs faster than that of $\mathrm{HO}-1^{+/+}$mice, suggesting HDLs of $\mathrm{HO}-1^{-/-}$and ${ }^{+/-}$mice are more negatively charged or smaller in size (Figure 2(a)). To examine the composition of apolipoproteins in HDL, $1 \mu \mathrm{g}$ HDL was subjected to 420\% SDS-PAGE gel. The ratios of apolipoprotein AI and apolipoprotein AII were different among three genotypes (Figure 2(b)). Apolipoprotein AI was major protein in HO$1^{+/+}$, whereas apolipoprotein AII was a major in $\mathrm{HO}-1^{-/-}$ mice. The ratios of apolipoprotein AI to AII were 2.6, 1.1 , and 0.2 in $\mathrm{HO}_{-} 1^{+/+},{ }^{+-}$, and ${ }^{-/-}$mice, respectively, by densitometric analyzes. There are more than 10-fold changes of the ratio of apolipoprotein AI to AII between $\mathrm{HO}-1^{+/+}$and $\mathrm{HO}-1^{-/-}$mice. Studies using transgenic mice models suggested that apolipoprotein AI is antiatherogenic [29] and apolipoprotein AII is atherogenic [23]. Though we cannot explain the mechanism why the absence of HO-1 
resulted in the compositional change of HDL and produced oxidized HDL, it may be possible to understand HO-1 functions to prevent HDL particle and apolipoproteins from oxidative stress. It is reported that apolipoprotein AI starts denaturation and is easy to make oligomers in oxidized HDL [30]. However, in this study, we did not find oligomeric bands. It will be also interesting to examine whether HO$1^{-/-}$mice have more susceptibilities to atherogenesis by high-fat diet challenges.

Paraoxonase is a calcium-dependent esterase that is known to catalyze hydrolysis of organophosphates and widely expressed in the liver, kidney, intestine, and plasma [31]. Paraoxonase has been suggested to contribute to antioxidant protection of HDL to LDL oxidation in vitro [32] and in vivo [33]. HO- $1^{-/-}$mice had decreased plasma paraoxonase activity less than $50 \%$ compared to $\mathrm{HO}-1^{+/+}$mice (Figure 3(a)). This reduced paraoxonase activity may imply that HDL in $\mathrm{HO}-1^{-/-}$mice was suffered by stronger oxidative stress. There may be unknown relationship between reduced paraoxonase activity and the compositional changes of apolipoprotein AI to AII. Plasma lipid peroxides levels of $\mathrm{HO}-1^{-/-}$mice were higher than those of $\mathrm{HO}-1^{+/+}$mice (Figure 3(b)), suggesting that HO-1 functions to suppress lipoprotein oxidation presumably by production of antioxidants, biliverdin and bilirubin.

Over $95 \%$ of $\mathrm{HO}^{-1} 1^{-/-}$mice die in utero with unknown reason [4]. It may be not easy for $\mathrm{HO}_{-1}^{-/-}$mice to survive without intrinsic antioxidant systems although the reason only a part of those survives is not still clear. In addition, changes in $\mathrm{HO}-1^{-/-}$mice such as lower body weight and decrease of plasma triglyceride need to be further examined by analyzing food consumption and metabolic rate. However, our data using $\mathrm{HO}-1^{-/-}$mice directly suggests a significant function of $\mathrm{HO}-1$ as an anti-inflammatory molecule in artery wall and for native HDL.

\section{Abbreviations}

HO: Heme oxygenase

HDL: High-density lipoprotein

LDL: Low-density lipoprotein

oxLDL: Oxidized LDL

$-/-$ : Homozygous knockout

$+/-$ : Heterozygous knockout

$+/+$ Wild type.

\section{References}

[1] M. D. Maines and A. Kappas, "Cobalt induction of hepatic heme oxygenase; with evidence that cytochrome P-450 is not essential for this enzyme activity," Proceedings of the National Academy of Sciences of the United States of America, vol. 71, no. 11, pp. 4293-4297, 1974.

[2] M. D. Maines, N. G. Ibrahim, and A. Kappas, "Solubilization and partial purification of heme oxygenase from rat liver," Journal of Biological Chemistry, vol. 252, no. 16, pp. 59005903, 1977.

[3] T. Yoshida and G. Kikuchi, "Purification and properties of heme oxygenase from pig spleen microsomes," Journal of Biological Chemistry, vol. 253, no. 12, pp. 4224-4229, 1978.
[4] K. D. Poss and S. Tonegawa, "Reduced stress defense in heme oxygenase 1-deficient cells," Proceedings of the National Academy of Sciences of the United States of America, vol. 94, no. 20, pp. 10925-10930, 1997.

[5] R. Stocker and M. A. Perrella, "Heme oxygenase-1: a novel drug target for atherosclerotic diseases?" Circulation, vol. 114, no. 20, pp. 2178-2189, 2006.

[6] R. Stocker, Y. Yamamoto, A. F. McDonagh, A. N. Glazer, and B. $\mathrm{N}$. Ames, "Bilirubin is an antioxidant of possible physiological importance," Science, vol. 235, no. 4792, pp. 1043-1046, 1987.

[7] K. Kawamura, K. Ishikawa, Y. Wada et al., "Bilirubin from heme oxygenase-1 attenuates vascular endothelial activation and dysfunction," Arteriosclerosis, Thrombosis, and Vascular Biology, vol. 25, no. 1, pp. 155-160, 2005.

[8] E. C. Theil, "Regulation of ferritin and transferrin receptor mRNAs," Journal of Biological Chemistry, vol. 265, no. 9, pp. 4771-4774, 1990.

[9] G. Balla, H. S. Jacob, J. Balla et al., "Ferritin: a cytoprotective antioxidant strategem of endothelium," Journal of Biological Chemistry, vol. 267, no. 25, pp. 18148-18153, 1992.

[10] J. R. Stone and M. A. Marletta, "Soluble guanylate cyclase from bovine lung: activation with nitric oxide and carbon monoxide and spectral characterization of the ferrous and ferric states," Biochemistry, vol. 33, no. 18, pp. 5636-5640, 1994.

[11] S. W. Ryter, J. Alam, and A. M. K. Choi, "Heme oxygenase1/carbon monoxide: from basic science to therapeutic applications," Physiological Reviews, vol. 86, no. 2, pp. 583-650, 2006.

[12] K. Ishikawa, M. Navab, N. Leitinger, A. M. Fogelman, and A. J. Lusis, "Induction of heme oxygenase-1 inhibits the monocyte transmigration induced by mildly oxidized LDL," Journal of Clinical Investigation, vol. 100, no. 5, pp. 1209-1216, 1997.

[13] K. Ishikawa, D. Sugawara, X. P. Wang et al., "Heme oxygenase1 inhibits atherosclerotic lesion formation in LDL-receptor knockout mice," Circulation Research, vol. 88, no. 5, pp. 506$512,2001$.

[14] M. S. Brown, Y. K. Ho, and J. L. Goldstein, “The cholesteryl ester cycle in macrophage foam cells. Continual hydrolysis and re-esterification of cytoplasmic cholesteryl esters," Journal of Biological Chemistry, vol. 255, no. 19, pp. 9344-9352, 1980.

[15] A. D. Watson, J. A. Berliner, S. Y. Hama et al., "Protective effect of high density lipoprotein associated paraoxonase. Inhibition of the biological activity of minimally oxidized low density lipoprotein," Journal of Clinical Investigation, vol. 96, no. 6, pp. 2882-2891, 1995.

[16] M. Aviram, M. Rosenblat, C. L. Bisgaier, R. S. Newton, S. L. Primo-Parmo, and B. N. La Du, "Paraoxonase inhibits highdensity lipoprotein oxidation and preserves its functions: a possible peroxidative role for paraoxonase," Journal of Clinical Investigation, vol. 101, no. 8, pp. 1581-1590, 1998.

[17] W. A. Boisvert, A. S. Black, and L. K. Curtiss, "ApoA1 reduces free cholesterol accumulation in atherosclerotic lesions of apoE-deficient mice transplanted with apoE-expressing macrophages," Arteriosclerosis, Thrombosis, and Vascular Biology, vol. 19, no. 3, pp. 525-530, 1999.

[18] M. Navab, S. T. Reddy, B. J. Van Lenten, G. M. Anantharamaiah, and A. M. Fogelman, "The role of dysfunctional HDL in atherosclerosis," Journal of Lipid Research, vol. 50, pp. S145S149, 2009.

[19] Y. Takahashi, H. Chiba, K. Matsuno et al., "Native lipoproteins inhibit platelet activation induced by oxidized lipoproteins," Biochemical and Biophysical Research Communications, vol. 222, no. 2, pp. 453-459, 1996.

[20] K. D. Poss and S. Tonegawa, "Heme oxygenase 1 is required for mammalian iron reutilization," Proceedings of the National 
Academy of Sciences of the United States of America, vol. 94, no. 20, pp. 10919-10924, 1997.

[21] M. P. Soares, Y. Lin, J. Anrather et al., "Expression of heme oxygenase-1 can determine cardiac xenograft survival," Nature Medicine, vol. 4, no. 9, pp. 1073-1077, 1998.

[22] J. H. Qiao, P. Z. Xie, M. C. Fishbein et al., "Pathology of atheromatous lesions in inbred and genetically engineered mice: genetic determination of arterial calcification," Arteriosclerosis and Thrombosis, vol. 14, no. 9, pp. 1480-1497, 1994.

[23] C. H. Warden, C. C. Hedrick, J. H. Qiao, L. W. Castellani, and A. J. Lusis, "Atherosclerosis in transgenic mice overexpressing apolipoprotein A-II," Science, vol. 261, no. 5120, pp. 469-472, 1993.

[24] R. J. Havel, H. A. Eder, and J. H. Bragdon, "The distribution and chemical composition of ultracentrifugally separated lipoproteins in human serum," The Journal of Clinical Investigation, vol. 34, no. 9, pp. 1345-1353, 1955.

[25] O. H. Lowry, N. J. Rosebrough, A. L. Farr, and R. J. Randall, "Protein measurement with the Folin phenol reagent," The Journal of Biological Chemistry, vol. 193, no. 1, pp. 265-275, 1951.

[26] U. K. Laemmli, "Cleavage of structural proteins during the assembly of the head of bacteriophage T4," Nature, vol. 227, no. 5259, pp. 680-685, 1970.

[27] K. N. Gan, A. Smolen, H. W. Eckerson, and B. N. La Du, "Purification of human serum paraoxonase/arylesterase. Evidence for one esterase catalyzing both activities," Drug Metabolism and Disposition, vol. 19, no. 1, pp. 100-106, 1991.

[28] D. Willis, A. R. Moore, R. Frederick, and D. A. Willoughby, "Heme oxygenase: a novel target for the modulation of the inflammatory response," Nature Medicine, vol. 2, no. 1, pp. 8790, 1996.

[29] E. M. Rubin, R. M. Krauss, E. A. Spangler, J. G. Verstuyft, and S. M. Clift, "Inhibition of early atherogenesis in transgenic mice by human apolipoprotein A1," Nature, vol. 353, no. 6341, pp. 265-267, 1991.

[30] R. L. Artola, C. B. Conde, L. Bagatolli, R. P. Pécora, G. D. Fidelio, and S. C. Kivatinitz, "High-density lipoprotein from hypercholesterolemic animals has peroxidized lipids and oligomeric apolipoprotein A-I. Its putative role in atherogenesis," Biochemical and Biophysical Research Communications, vol. 239, no. 2, pp. 570-574, 1997.

[31] G. S. Getz and C. A. Reardon, "Paraoxonase, a cardioprotective enzyme: continuing issues," Current Opinion in Lipidology, vol. 15, no. 3, pp. 261-267, 2004.

[32] M. I. Mackness, S. Arrol, and P. N. Durrington, "Paraoxonase prevents accumulation of lipoperoxides in low-density lipoprotein," FEBS Letters, vol. 286, no. 1-2, pp. 152-154, 1991.

[33] D. M. Shih, L. Gu, Y. R. Xia et al., "Mice lacking serum paraoxonase are susceptible to organophosphate toxicity and atherosclerosis," Nature, vol. 394, no. 6690, pp. 284-287, 1998. 


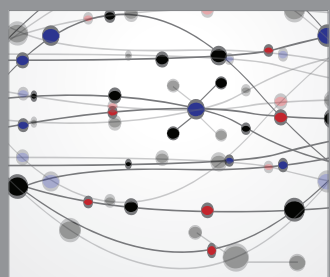

The Scientific World Journal
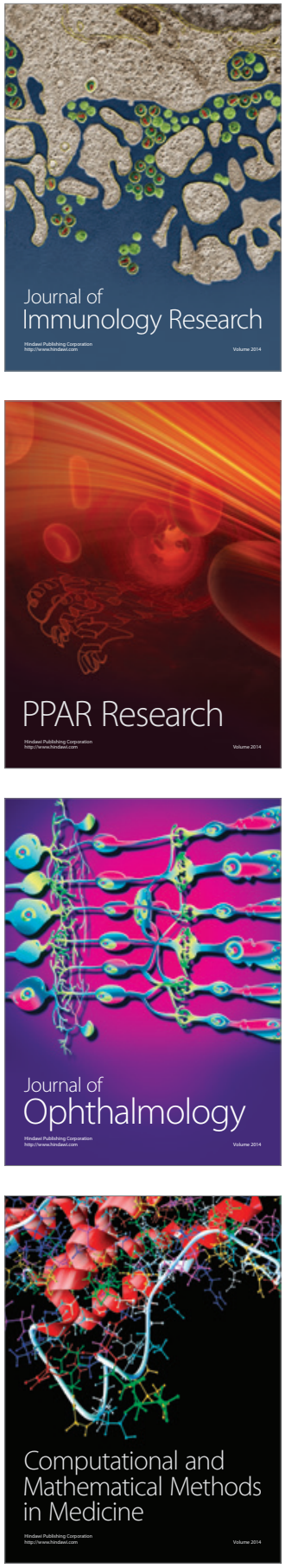

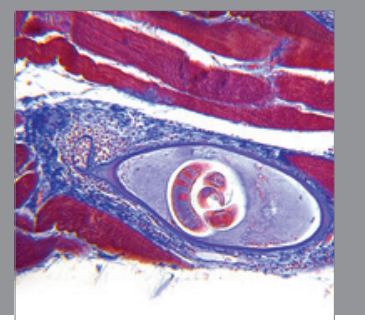

Gastroenterology

Research and Practice
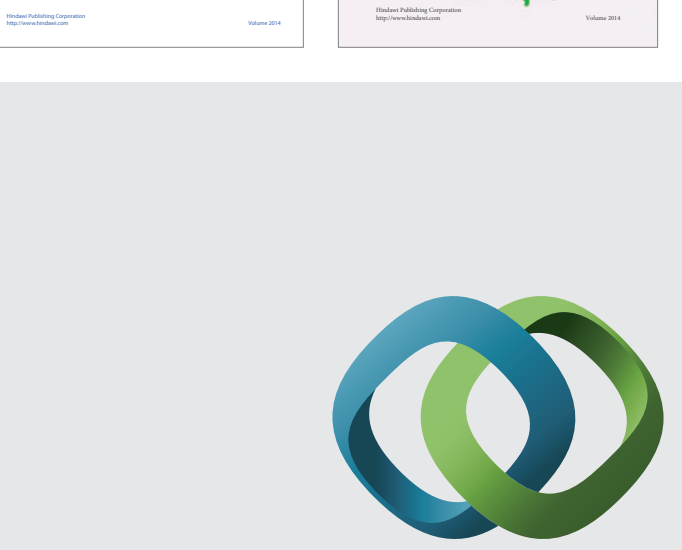

\section{Hindawi}

Submit your manuscripts at

http://www.hindawi.com
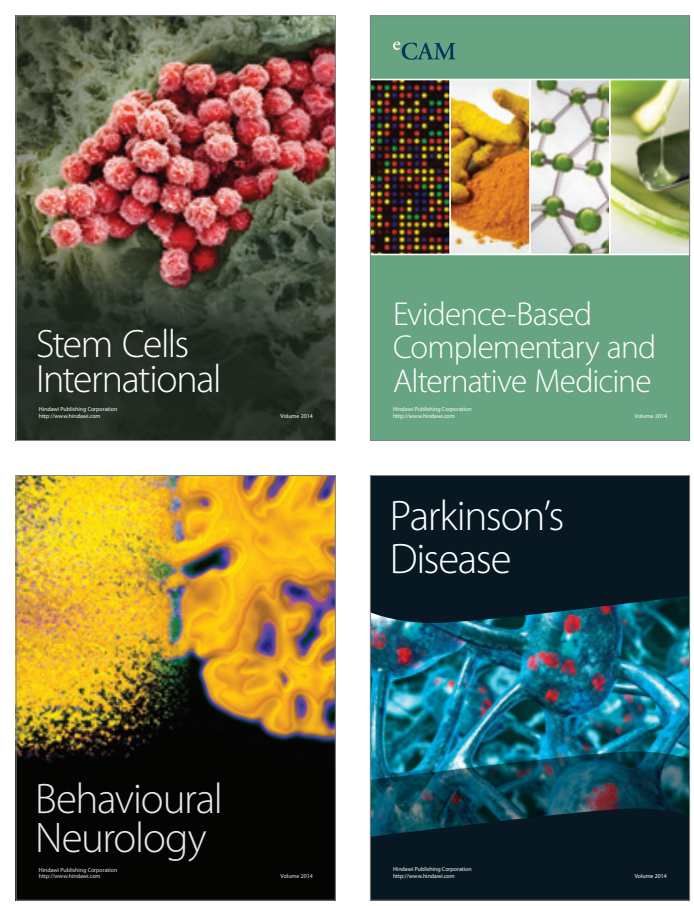

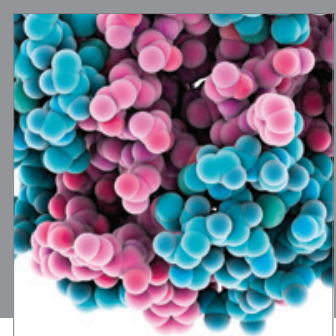

Journal of
Diabetes Research

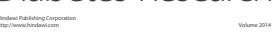

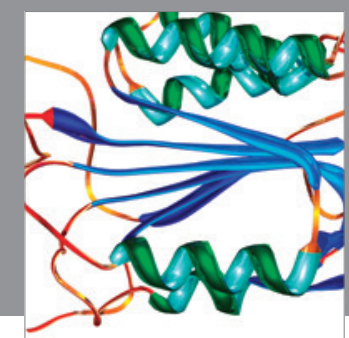

Disease Markers
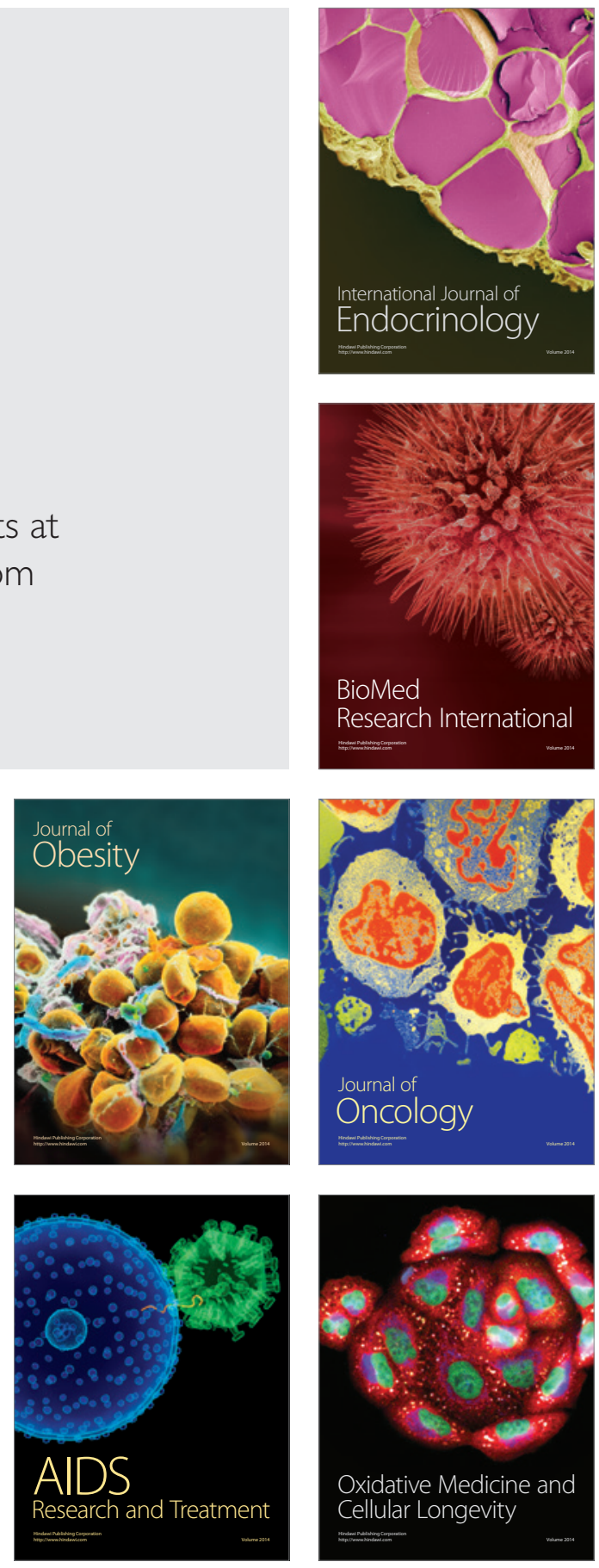